\title{
Seismic Vulnerability Assessment of Coupled Wall RC Structures
}

\author{
Ramin Taghinezhad \\ Research Assistant \\ Department of Civil and \\ Environmental Engineering \\ Florida International University \\ USA
}

\author{
Arash Taghinezhad \\ Graduate Research Assistant \\ Department of Construction \\ Management \\ Louisiana State University \\ USA
Vafa Soltangharaei
Graduate Research Assistant
Department of Civil and
Environmental Engineering
University of South Carolina \\ USA
}

\author{
Vahid Mahdavifar (PI) \\ Post-doctoral Research Associate \\ Department of Environmental \\ Conservation \\ University of Massachusetts \\ Amherst, USA
}

\begin{abstract}
Swiss Federal Institute of Technology developed a simple method to evaluate seismic vulnerability of reinforced concrete buildings with structural walls using an engineering approach. The objective of this research was the evaluation of the developed method through the capacity curve with a focus on the buildings with frame action due to the coupling of the walls by piers and spandrels. For this purpose, a numerical model of a six-story reinforced concrete structure with sixteen structural walls was created in two directions and nonlinear static analysis was performed to obtain the capacity curve under different lateral load patterns. It was found that there is an appropriate overlap between the numerical model and developed method in terms of capacity curve and vulnerability.
\end{abstract}

Keywords: concrete, nonlinear static analysis, reinforced concrete buildings, seismic vulnerability, structural shear wall,

\section{INTRODUCTION}

Reinforced concrete structures with the structural walls are often classified into three types: structural wall systems with negligible frame action, Structural wall systems with separate frame action, and structural wall systems with frame action due to the coupling of the walls [1]. The first type includes slender reinforced concrete walls, which carry lateral loads and columns carry gravity loads without frame-wall interaction. In the second type, a moment resisting frame is created in the structure by rigid connections between beams and columns, and the structural walls carry lateral loads. The third type consists of structural walls that carry both gravity and lateral forces. There are no gravity columns in this system. In fact, the

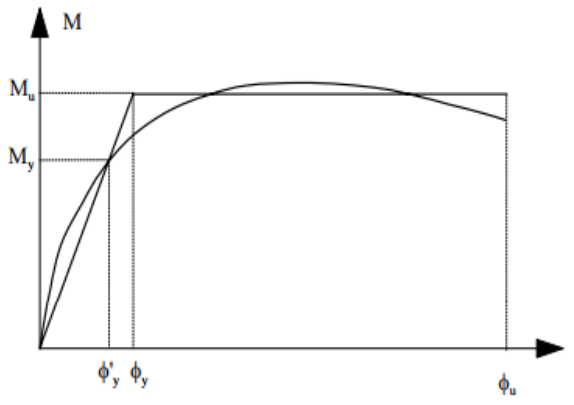

a)

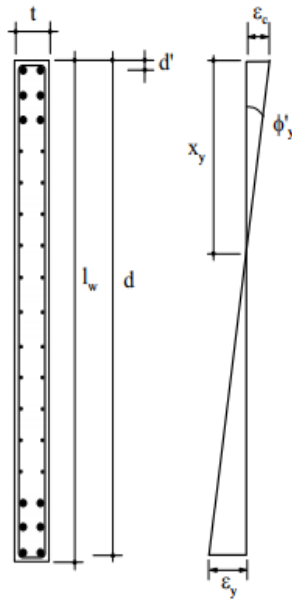

b)

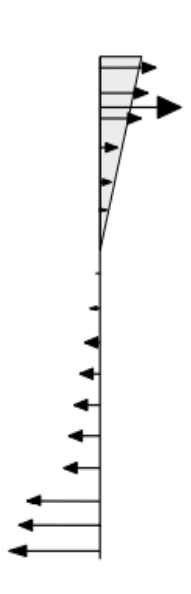

c)

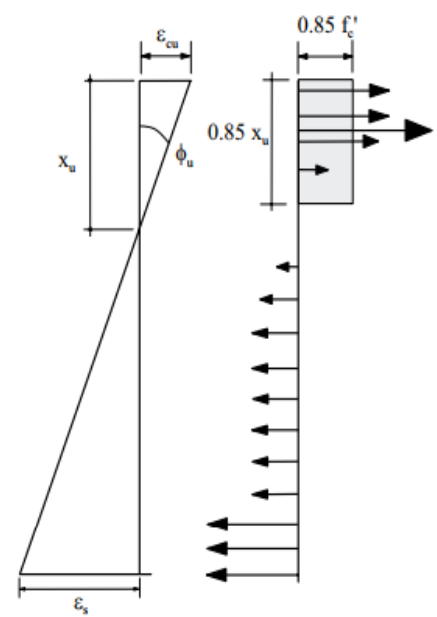

d)

Figure 1: (a) Bilinear moment-curvature diagram, (b) wall section, (c) strain and force diagram on initial yielding, and (d) strain and force diagram in the ultimate level [1]. 
coupling between pier and spandrel carries lateral forces. Structural walls are also would potentially be arranged in a network of walls interconnected with each other to make a rigid box which is called shear core wall. The core is used to provide lateral stiffness required for the buildings in concrete frame structures [2] or non-concrete structures such as mass timber buildings $[3,4]$.

In this paper, in addition to outlining the vulnerability assessment of the third type of structural wall systems, presented by Swiss Federal Institute of Technology [1], an example of this type of structures was given and evaluated using nonlinear static analysis. To this end, structure capacity curves were derived using the analytical method. Generally, two methodologies can be utilized for deriving capacity curves: experimental and analytical. Two analytical methods of incremental nonlinear time history and nonlinear static (pushover) analysis are recommended for this purpose. Some researchers extracted the capacity curves of multi-story structures using incremental time history analyses [5-10] Several time history analyses were conducted by applying different earthquake acceleration records and with different intensity scales. Although this method presents more realistic behavior of structures, it is very time consuming and more sensitive to the modeling and analytical parameters. Therefore, review of the literature reveals that nonlinear static analyses have gained more practical application instead of the nonlinear time history analysis [11-19]. To derive capacity curve in experimental tests, the loading increase step by step at the location of force until the final collapse of the structure or major drop in strength [20-21]. In this study, the nonlinear static analysis was employed to derive the capacity curves of a reinforced concrete structure. Finally, a comparison between results from nonlinear static analysis and developed method by Swiss Federal Institute of Technology was made.

\section{METHODOLOGY}

\subsection{Moment-Curvature Equation in the Reinforced Concrete Wall Section}

In concrete wall sections, with the distribution of the reinforcement throughout the cross-section, moment-curvature equations can be roughly drawn as bilinear curves as described in Fig. 1. This curve is characterized by two points: $\left(\varphi_{y}^{\prime}, M_{y}\right)$ which indicates the first yield of tensile reinforcement, and $\left(\varphi_{u}, M_{u}\right)$ indicates the ultimate compressive flexural strength of concrete. The curvature of the first yield can be determined from the following equation according to (Fig.1 (c)):

$$
\varphi_{y}^{\prime}=\frac{\varepsilon_{y}}{d-X_{y}}
$$

$\varepsilon_{y}=f_{y} / E_{S}:$ Yield Strain of the reinforcement

$f_{y}:$ Yield strength of the reinforcement

$E_{s}$ : Elastic modulus of elasticity in the reinforcement

$d$ : Distance from compression face to tension reinforcement, $X_{y}:$ Neutral axial depth

The final curvature $\varphi_{u}$ is also determined from the following equation (Fig. 1 (d)):

$$
\varphi_{u}=\frac{\varepsilon_{c u}}{X_{u}}
$$

$\varepsilon_{c u}$ : The final compression strain in the concrete $X_{u}:$ Neutral axial depth.

According to Fig. 1, the nominal yield curvature and ductility of the wall section are also defined as follows:

$$
\varphi_{y}=\varphi_{y}^{\prime} \frac{M_{u}}{M_{y}}, \mu_{\varphi}=\frac{\varphi_{u}}{\varphi_{y}}
$$

According to Fig. 1 and curvature in a structural wall ( $\varphi=M / E I)$, the yielding displacement at the top of the wall for different force distributions is obtained from:

$$
\Delta_{y}=\chi \varphi_{y} H_{t o t}^{2}
$$

In the force distribution which is close to the first mode, the coefficient $\chi$ is varied from 0.17 for the single force at top and 0.276 for the triangular force distribution, once $\chi=0.2$ was suggested [1]. The final displacement at the top of the wall is also obtained from the following equation:

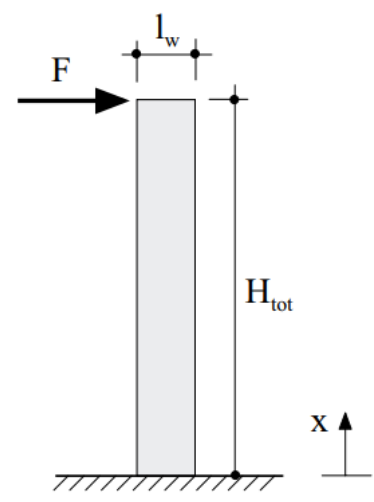

cantilever wall with equivalent force

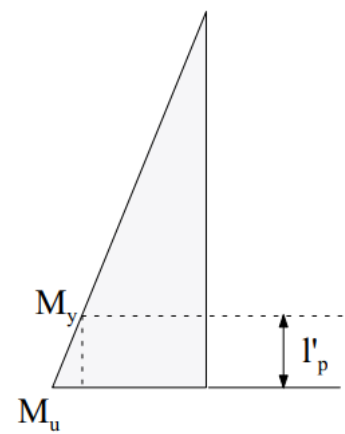

moment distribution

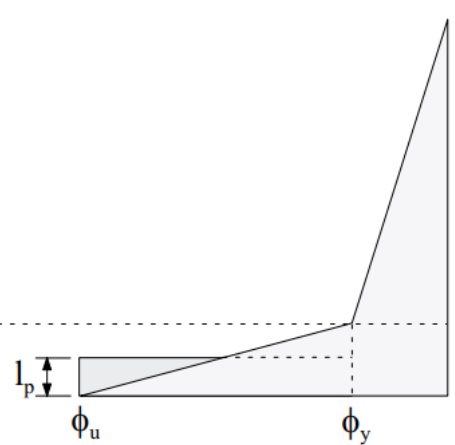

curvature

distribution

Figure 2: Cantilever wall under single horizontal force and distribution of moment and curvature [1]. 


$$
\Delta_{u}=\mu_{w} \Delta_{y}
$$

$\mu_{w}$ is the ductility of a wall and it is expressed as follows in terms of $\mu_{\varphi}$ :

$\mu_{w}=1+\frac{1}{\chi H_{t o t}^{2}}\left(\mu_{\varphi}-1\right) l_{p}\left(H_{t o t}-\frac{l_{p}}{2}\right)$

According to Fig. 2, which shows a moment-curvature curve for a wall with a single horizontal force, $l_{p}{ }^{\prime}$ is the height of the wall that the reinforcement starts to yield, in another word, it is the height with the yielding moment $\left(M(x)=M_{y}\right)$. Therefore, in the length of the wall where nonlinearity starts to develop. This length is called $l_{p}$ or the length of the plastic hinge.

$$
M\left(x=l_{p}\right)=M_{Y}=M_{u}\left(1-\frac{l_{p}}{H_{t o t}}\right)
$$

Assuming linear expansion of curvature from $\varphi_{y}$ to $\varphi_{u}$ :

$$
l_{p}=\frac{H_{t o t}}{2}\left(1-\frac{M_{y}}{M_{u}}\right)
$$

In the triangular distribution of lateral force, Eq. (9) is expressed as follows [1]:

$$
\begin{gathered}
M\left(x=l_{p}\right)=M_{y}=M_{u}\left[\left(1+\frac{1}{2}\left(\frac{l_{p}}{H_{t o t}}\right)^{3}-\frac{3}{2}\left(\frac{l_{p}}{H_{t o t}}\right)\right](9)\right. \\
l_{p}=2 H_{t o t} \cos \left(\frac{\phi}{3}+\frac{4}{3} \pi\right), \cos \phi=\frac{1}{2}\left(\frac{M_{y}}{M_{u}}-1\right)
\end{gathered}
$$

lp: Length of the plastic hinge

l'p: Height of region over which reinforcement has yielded

\subsection{Reinforced Concrete Structural Capacity Curve}

The structural capacity curve is a plot based on the base shear $V_{b}$ and the maximum roof displacement $\Delta$, which is obtained from the superposition of the wall capacity curves. The bilinear wall capacity curve is defined by three parameters of the wall shear capacity $V_{m}$, the yield displacement over the wall $\Delta_{y}$, and the final displacement over the wall $\Delta_{u}$. In the following, the method of determining the capacity curve for structural wall systems with frame action due to the coupling of the walls is explained.

The range of the coupling effect is expressed by a parameter that is called zero moment height [1], which is a function of the spandrel flexural stiffness of the wall flexural stiffness $\left(E I_{s p} / l_{0}\right) /\left(E I_{p} / h_{s t}\right)$. Considering $h_{0}$ is the height of zero moment and $M_{u}$ is the ultimate bending capacity of the wall, the shear capacity and yield displacement over the wall are determined by the following equations:

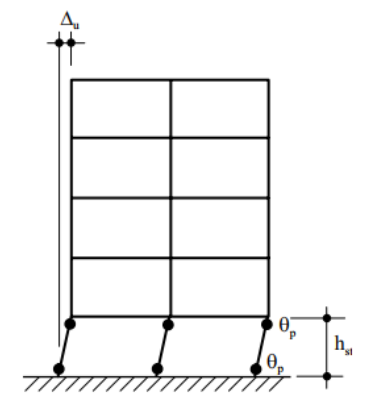

b)

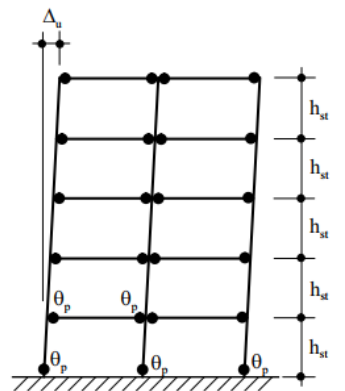

a)

Figure 3: Ultimate displacement for (a) the spandrel mechanism, (b) the pier mechanism [1].

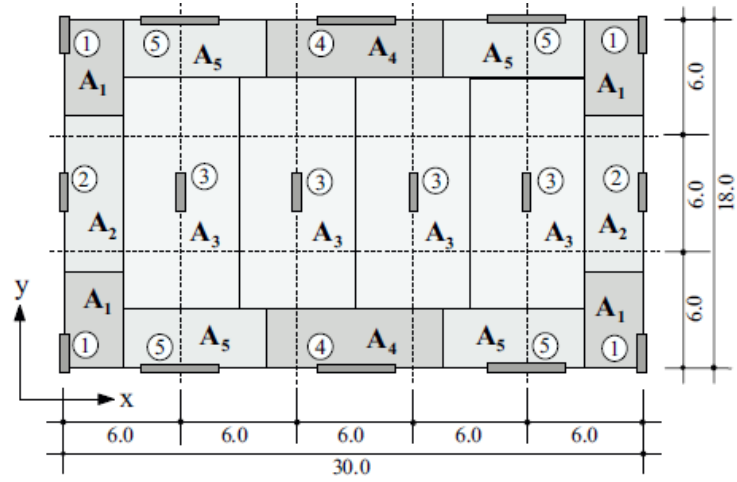

a)
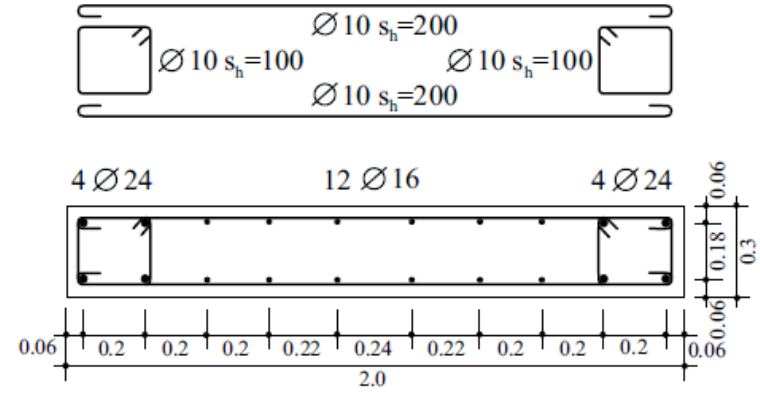

b)

Figure 4: Building detail (a) building plan, and (b) structural walls details in y-direction [1]. 


$$
\begin{aligned}
& V_{m}=\frac{M_{u}}{h_{0}} \\
& \Delta_{y}=V_{m} H_{t o t}\left(\frac{h_{p}\left(3 h_{0}-h_{p}\right)}{6 E I_{\text {eff }}}+\frac{K}{G A_{\text {eff }}}\right)
\end{aligned}
$$

The second part of the Eq. (12), shear ductility, is usually negligible. Given the Fig. (1), the effective stiffness of the cracked section can be determined based on the momentcurvature curve:

$$
E I_{e f f}=\frac{M_{y}}{\varphi_{y}^{\prime}}
$$

The ultimate displacement at top of the wall $\Delta_{u}$ is a function of the rotational ductility $\mu_{\varphi}$ and the type of mechanism. Depending on the bending strength, joints may be formed in the spandrel or the pier [3].

In the spandrel mechanism (Fig. 3 (a)) and the pier mechanism (Fig. 3(b)), the ultimate displacement is obtained from the following equations [1]:

$$
\Delta_{u, s s m}=\Delta_{y}+\left(H_{t o t}-\frac{l_{p}}{2}\right) \theta_{p}=\Delta_{y}+\left(n h_{s t}-\frac{l_{p}}{2}\right)\left(Q_{u}-Q_{y}\right) l_{p}
$$

$$
\Delta_{u, p s m}=\Delta_{y}+\left(h_{s t}-\frac{l_{p}}{2}\right) \theta_{p}=\Delta_{y}+\left(h_{s t}-\frac{l_{p}}{2}\right)\left(Q_{u}-Q_{y}\right) l_{p}
$$

With the insertion of the Eq. (12), for $\Delta_{y}$ and ignoring the shear ductility, the ductility of the structural wall, for a combination of spandrel mechanism and the pier mechanism is equal to [3]:

$$
\mu_{w}=1+\left(\mu_{\varphi}-1\right) \frac{6 h_{0} l_{p}}{H_{t o t} h_{p}\left(3 h_{0}-h_{p}\right)}\left(\beta h_{s t}-\frac{l_{p}}{2}\right), 1 \leq \beta \leq n
$$

In this way, the parameters defined in the bilinear capacity curve is determined by the coupling action. Building capacity curve is obtained in one direction from the superposition of the capacity curves of the walls in that direction.

Table 1: Material property used in the building.

\begin{tabular}{ccccc}
\hline Structural Element & $E_{S}(\mathrm{GPa})$ & $f_{y}(\mathrm{MPa})$ & $E_{C}(\mathrm{GPa})$ & $f_{c}^{\prime}(\mathrm{MPa})$ \\
\hline Wall & 210 & 500 & 37.5 & 45 \\
\hline floor & 210 & 460 & 30 & 28
\end{tabular}

Table 2: Summary of results for 3 structural walls in y-direction [1].

\begin{tabular}{cccccccccc}
\hline Wall & $h_{0} / h_{p}$ & $M_{Y}(k N . m)$ & $\varphi_{Y}(1 / m)$ & $M_{U}(k N . m)$ & $\varphi_{U}(1 / m)$ & $\mu_{\varphi}$ & $l_{p}$ & $E I_{e f f}\left(M N . m^{2}\right)$ & $V_{m}(k N)$ \\
\hline 1 & 1.7 & 5955 & 0.0025 & 7318 & 0.0179 & 7.29 & 0.54 & 2980 & 1266 \\
2 & 1.7 & 3521 & 0.0026 & 5279 & 0.0306 & 11.83 & 1.029 & 2043 & 863 \\
3 & 1.8 & 3034 & 0.0026 & 4786 & 0.0285 & 10.87 & 1.12 & 1824 & 782 \\
\hline
\end{tabular}

\begin{tabular}{ccccc}
\hline Wall & $\Delta_{y}(\mathrm{~mm})$ & $\Delta_{u, p s m}(\mathrm{~mm})$ & $\Delta_{u, s s m}(\mathrm{~mm})$ & $k_{\text {eff }}(K N . m)$ \\
\hline 1 & 68 & 94 & 236 & 18494 \\
2 & 73 & 155 & 640 & 11015 \\
3 & 74 & 157 & 650 & 10545 \\
\hline
\end{tabular}

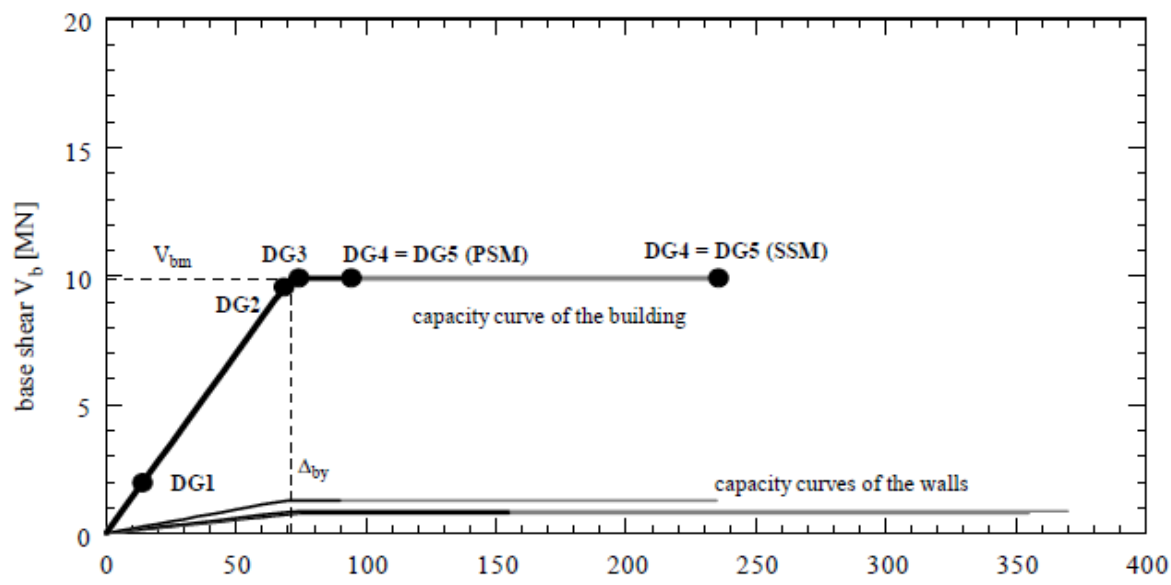

Figure 5: Capacity curve of reinforced concrete structure in y-direction [1]. 
Table 3: Summary of results for three types of structural walls in y-direction [1]

\begin{tabular}{cccc}
\hline Wall & 3 & 2 & 1 \\
\hline$V_{c r}(k N)$ & 465 & 199 & 148 \\
$\Delta_{c r}(m m)$ & 25 & 17 & 14 \\
\hline
\end{tabular}

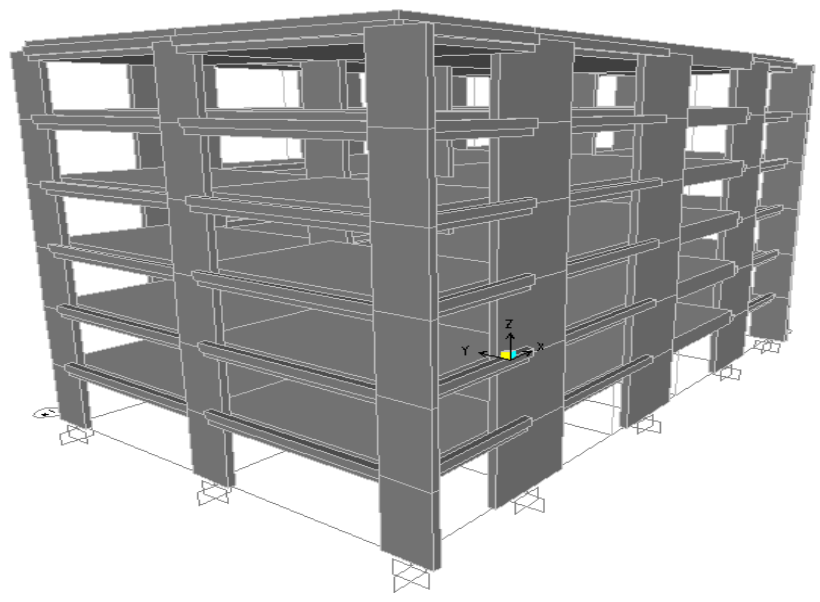

Figure 6: 3D view of the numerical model.

\section{CASE STUDY BUILDING}

Fig. 4 shows a 6-story concrete building with structural walls. Each floor has a height of 3.4 meters and sixteen walls. Material properties are presented in Table 1. These walls are classified into five types (A1 to A5), according to their positions and loading levels. The thickness of the slabs is $24 \mathrm{~cm}$ and the depth of the beams under the floor is $40 \mathrm{~cm}$ in the wall axis. The load on the floor is assumed to be $12.5 \mathrm{kN} / \mathrm{m}^{2}$ by considering the wall weight. All existing walls in y-direction have a length of 2 meters, which is shown in its structural detail Fig. 4 (b). In Table 1, and Table 2, material properties and a summary of the results based on the presented equations for three types of walls in the y-direction are presented. Therefore, the bilinear capacity curves of these walls can be extracted, and consequently, the bilinear capacity curve of the building is obtained in the $y-$ direction with superposition (Fig. 5) [1].

\subsection{Damage Definition in Accordance with European Macroseismic Scale (EMS)}

Five levels of vulnerability are defined for the reinforced concrete structures, which are determined as specific points on the bilinear capacity curve of the structure [1].

Damage level 1: At this stage, minor structural and nonstructural damages are observed. In fact, at this stage, cracks appear at the base of the walls. To determine this stage, the shear force, in which the first cracks appear, is calculated from the capacity curve. The critical moment (Mcr) occurs in Wall No. 1 is $905 \mathrm{kN}$, at the depth of $1.2 \mathrm{~m}\left(x_{c r}=1.2 \mathrm{~m}\right)$. The following results are obtained for the walls in the y-direction, using the presented equations (Table 3 ). Therefore, in the smallest displacement, which is in Wall No. 1, the first crack $\left(\Delta_{c r}=14 \mathrm{~mm}\right)$ appears. Thus, the sum of $V_{c r}$ is obtained for all the walls $\left(V_{c r}=1960 \mathrm{kn}\right)$. Moreover, the coordinate of Dcr $=14 \mathrm{~mm}$ and $\mathrm{Vcr}=1960 \mathrm{kN}$ on the capacity curve represents the point at which the building enters in the first stage of damage (Fig. 5).
Damage level 2 is a moderate damage which is defined as a level that partial structural damage and moderate non-structural damage occur. In fact, at this stage, the damage appears as the cracks in the structural walls. Before this stage, the behavior of the structure is linear and at this stage, the building starts to behave nonlinearly. To determine the coordinate of the capacity curve, the displacement where the first wall enters into the yielding stage $\left(\Delta_{y}, \min \right)$ is used, which is related to Wall No. $3\left(\Delta_{y 3}=68 \mathrm{~mm}\right)$. The base shear for this displacement is $9570 \mathrm{kN}(\mathrm{Vb}=9570 \mathrm{kN})$. Therefore, the mentioned point with a displacement of $68 \mathrm{~mm}$ and a load of $9570 \mathrm{kN}$ is the location on the curve where the structure has entered into the damage level 2 (Fig. 5).

Damage level 3 is the severe damage initiation which moderate structural damage and severe non-structural damage happen. At this stage, a spalling of concrete and buckling of reinforcements occurs. The structure extends into the nonlinear region and finally the last wall yields. This degree of damage is determined by the capacity curve from the largest displacement of walls yield $\left(\Delta_{y, \max }\right)$ which is related to Wall No. $1\left(\Delta_{y 1}=74 \mathrm{~mm}\right)$, and the corresponding base shear is $9918 \mathrm{kN}$. At this point, the structure is in the damage level 3 (Fig. 5). According to Table 2 , the stiffness of the building in the y-direction is 139785 $\mathrm{kN} / \mathrm{m}$. The amount of displacement at the point of yield is obtained, given the total shear force $V_{b}=9918 k n$, with the assumption of the linearity of the capacity curve before the yield.

$$
\Delta_{b y}=\frac{V_{b m}}{K}=\frac{9918}{139785} \times 10^{3}=71 \mathrm{~mm}
$$

Damage level 4 is the severe damage which includes severe structural and non-structural damages. In this stage, the first structural wall reaches its ultimate displacement. This stage is determined by the smallest ultimate displacement of the wall, which is corresponding to Wall No. $3\left(\Delta_{u 3}=94 \mathrm{~mm}\right)$. The pier mechanism with the coordinates of $(94 \mathrm{~mm}, 9593 \mathrm{kn})$ and spandrel mechanism with the coordinates of $(236 \mathrm{~mm}, 9593 \mathrm{kn})$ indicate the points on the capacity curve, which the structure enters the fourth degree of damage.

Damage level 5 is structural collapse which includes very severe structural damages. At this stage, the building is collapsed. It happens when the last wall reaches its ultimate displacement. At this time, the base shear of the building will be reduced to less than two-thirds of its maximum. Therefore, points $(94 \mathrm{~mm}, 9593 \mathrm{kN})$ and $(236 \mathrm{~mm}, 9593 \mathrm{kN}) \quad$ indicate coordinates of damage levels 4 and 5, respectively (Fig. 5).

\subsection{Numerical modeling}

SAP2000 program was used to conduct the nonlinear static analysis for the building [22]. The column elements are used to model the structural walls [23]. Thus P-M interaction diagrams are produced for each column element. The floor diaphragms of the building are assumed to be rigid. Due to the problems related to numerical convergence, the columns and wall elements were divided into three parts. The shear and flexural hinges are considered in the numerical model as well. For the elements of the column and wall, the flexural hinges are assigned at the relative distance of 0.05 of the length of the elements at each end. The shear hinges are assigned in the middle of the element length. The beams and the coupling 
beams are modeled as frame elements with bending and shear hinges.

\section{Capacity Curve}

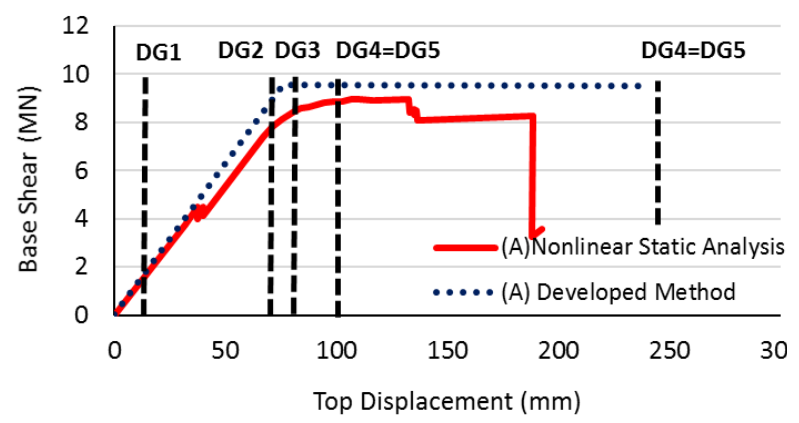

Capacity Curve

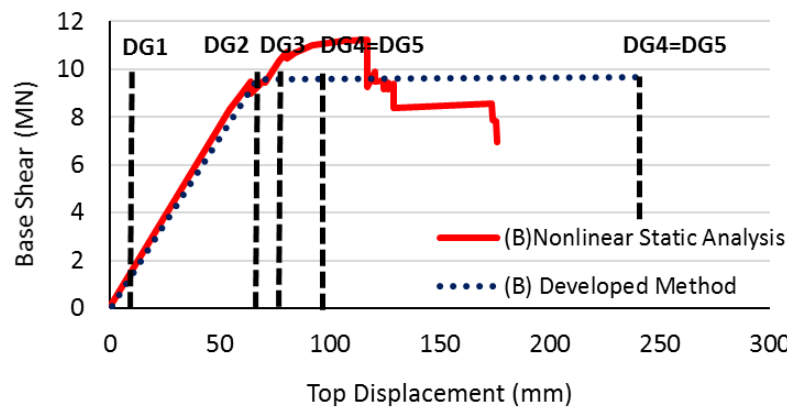

Capacity Curve

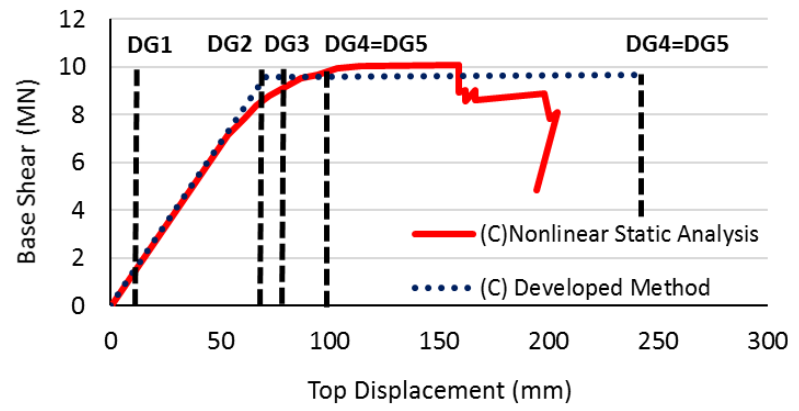

Figure 7: Capacity curves under different load patterns: (A) uniform acceleration, (B) IBC, and (C) first mode.

The numerical model subjected to three different lateral load patterns including uniform acceleration, IBC lateral load distribution, and first mode of vibration. After performing nonlinear static analysis, the structural capacity curves were extracted as shown in Fig. 7. The resulted capacity curves show a good agreement between the results of nonlinear static analysis under different lateral load patterns and the developed method by Swiss Federal Institute of Technology.

\section{CONCLUSION}

1. The capacity curve resulted from the uniform acceleration load pattern shows more vulnerability than the developed method by Swiss Federal Institute of Technology.

2. The capacity curve resulted from the IBC lateral load distribution shows less vulnerability than the developed method by Swiss Federal Institute of Technology.
3. Comparing between capacity curves obtained from the developed method by the Swiss Federal Institute of Technology and the nonlinear static analysis for all considered lateral load patterns shows that the proposed method appropriately estimates the capacity curve of concrete reinforced building with coupling between pier and spandrel.

4. Using structural walls with the frame action due to coupling behavior between the spandrels and piers can be considered as a reliable earthquake resisting system for high seismic regions for carrying the lateral and gravity load.

\section{REFERENCES}

[1] Swiss Federal Institute of Technology, 2002, Seismic vulnerability of existing building, Zurich.

[2] Oskouei, V.A. and Mahdavifar, V., 2013. Modeling of Two-Cell Concrete Cores for Investigation of Reliabality of Equivalent Column Method.

[3] Mahdavifar, V., 2017. Cyclic performance of connections used in hybrid cross-laminated timber (Ph.D. dissertation), Oregon State University, Oregon, USA.

[4] Mahdavifar, V., Barbosa, A., Sinha, A., Muszynski, L. and Gupta, R., 2017. Hysteretic behaviour of metal connectors for hybrid (high-and low-grade mixed species) cross laminated timber, WCTE 2016 World Conference on Timber Engineering, Vienna, Austria.

[5] Belejo, A. and Bento, R., 2016. Improved modal pushover analysis in seismic assessment of asymmetric plan buildings under the influence of one and two horizontal components of ground motions. Soil Dynamics and Earthquake Engineering, 87 , pp.1-15.

[6] Soltangharaei, V., Razi, M. and Gerami, M., 2016. Comparative Evaluation of Behavior Factor of SMRF Structures for Near and Far Fault Ground Motions. Periodica Polytechnica. Civil Engineering, 60(1), p.75.

[7] Soleimani, S., Aziminejad, A. and Moghadam, A.S., 2018. Approximate two-component incremental dynamic analysis using a bidirectional energy-based pushover procedure. Engineering Structures, 157, pp.86-95.

[8] Fanaie, N. and Ezzatshoar, S., 2014. Studying the seismic behavior of gate braced frames by incremental dynamic analysis (IDA). Journal of Constructional Steel Research, 99, pp.111-120.

[9] Soltangharaei, V., Razi, M. and Gerami, M., 2015. Behaviour factor of buckling restrained braced structures for near and far fault ground motions. International Journal of Structural Engineering, 6(2), pp.158-171.

[10] Chomchuen, P. and Boonyapinyo, V., 2017. Incremental dynamic analysis with multi-modes for seismic performance evaluation of RC bridges. Engineering Structures, 132, pp.2943.

[11] Mahdi, T. and Gharaie, V.S., 2011. Plan irregular RC frames: comparison of pushover with nonlinear dynamic analysis. Asian J Civil Eng Build Housing, 12(6), pp.679-690. 
[12] Yahmi, D., Branci, T., Bouchaïr, A. and Fournely, E., 2017. Evaluation of behaviour factors of steel momentresisting frames using standard pushover method. Procedia Engineering, 199, pp.397-403.

[13] Pan, X., Zheng, Z. and Wang, Z., 2017. Estimation of floor response spectra using modified modal pushover analysis. Soil Dynamics and Earthquake Engineering, 92, pp.472-487.

[14] Soltangharaei, V., Zarean, M., Mahdavifar, V., Taghinezhad, R. and Taghinezhad, A., 2017. Response Modification Factor for Cold-Formed Steel Structures Using Pushover Analysis. International Journal of Engineering Science, pp. 15875-15880.

[15] Li, S., Zuo, Z., Zhai, C. and Xie, L., 2017. Comparison of static pushover and dynamic analyses using RC building shaking table experiment. Engineering Structures, 136, pp.430440 .

[16] Taghinezhad, R., Taghinezhad, A., Mahdavifar, V. and Soltangharaei, V., Numerical Investigation of Deflection Amplification Factor in Moment Resisting Frames Using Nonlinear Pushover Analysis. International Journal of Innovations in Engineering and Science, pp. 1-7.

[17] Bocciarelli, M. and Barbieri, G., 2017. A numerical procedure for the pushover analysis of masonry towers. Soil Dynamics and Earthquake Engineering, 93, pp.162-171.

[18] Taghinezhadbilondy, Ramin. "Extending Use of Simple for Dead Load and Continuous for Live Load (SDCL) Steel Bridge System to Seismic Areas." (2016), Ph.D. dissertation.

[19] Azizinamini, Atorod, Aaron Yakel, Ardalan Sherafati, Ramin Taghinezhad, and Jawad H. Gull. "Flexible Pile Head in Jointless Bridges: Design Provisions for H-Piles in Cohesive Soils." Journal of Bridge Engineering 21, no. 3 (2016).

[20] Pham, Huy, Ramin Taghinezhad, and Atorod Azizinamini. Experimental Investigation of Redundancy of Twin Steel BoxGirder Bridges Under Concentrated Load. No. 17-03649. 2017.

[21] Mohammadi, Alireza, Jawad H. Gull, Ramin Taghinezhad, and Atorod Azizinamini. "Assessment and Evaluation of Timber Piles Used in Nebraska for Retrofit and Rating." (2014).

[22] Computers and Structures Inc. (CSI), SAP2000 Three Dimensional Static and Dynamic Finite Element Analysis and Design of Structures V8.4.5, Berkeley, California.

[23] Naeim, Farzad, ed. The Seismic Design Handbook. Springer Science \& Business Media, 2012. 